\title{
A "Fala Original" e a obra de arte: Uma reflexão acerca do processo criativo
}

Carlene Maria Dias Tenório

\begin{abstract}
RESUMO - Partindo das idéias de Merleau-Ponty a respeito da "fala original" e com base nos pressupostos da fenomenologia e do existencialismo, é feita uma reflexão comparativa do processo criativo na arte e na "fala original", buscando encontrar as semelhanças e vicissitudes inerentes a essas duas formas de criação.
\end{abstract}

Palavras-chave: Fala Original, processo criativo.

\section{The original speech and the work of art: A reflection concerning the creative process}

\begin{abstract}
Starting from Merleau-Pont's ideas about the "original speech" and based on the premises of phenomenology and existentialism, some comparative considerations are made about the creative process in the art work and in the "original speech", trying to find the similarities and vicissitudes that are inherent in these two forms of creation.
\end{abstract}

Key words: original speech, creative process.

Amatuzzi (1989), ao descrever os aspectos constitutivos do que MerleauPonty define como "fala original" ou "fala primeira", explica que esta fala é aquela que é formulada pela primeira vez. É uma fala nova, improvisada, surpreendente, pois formula inquietações, pensamentos e sentimentos que estão presentes pela primeira vez. Esta primeira vez, no entanto, não deve ser entendida no sentido cronológico, mas no sentido da novidade da vivência.

Gestalt Terapeuta; Mestre e Doutoranda em Psicologia Clínica pela Universidade de Brasília-UNB; exprofessora daUniversidade de Fortaleza-UNIFOR; professora doCentro Universitáriode Brasília-UNICEUB; membro efetivo da diretoria e do corpo docente do Instituto de Gestalt Terapia de Brasília-IGTB E-mail: igtb.@ zas.com.br 
Em contraposição ao conceito de "fala original", "primeira" ou "autêntica", Merleau-Ponty (1996) criou o conceito de fala "segunda" ou "banal", que diferente da primeira, corresponde à retomada de uma intenção significativa anterior, fazendo uso de significações disponíveis em arranjos talvez novos, mas que são de fato repetições.

"Na realidade, a fala falada é o produto enrijecido e objetivo que resulta das falas originais, que se cristaliza na língua disponível ou em seres culturais, formas de discurso, mas que, ao mesmo tempo e por ser exatamente isso, instrumentaliza outras falas" (A matuzzi, 1989, p.34).

Desse modo, como esclarece Amatuzzi (1989), a fala "secundária" é útil e dá continuidade, enquanto a fala original cria; uma depende da outra. Para todas as "falas banais", possuímos significações já formadas. Elas só suscitam em nós pensamentos segundos, que não exigem de nós nenhum esforço de expressão, nem pedem de nossos ouvintes nenhum esforço de compreensão.

$\mathrm{Na}$ "fala autêntica", se bem que eu parta de significações disponíveis, seu arranjo visa criar significações novas a partir do silêncio primordial; visa expressar carências mais profundas do que aquelas que são providas bem ou mal no cotidiano. A "fala banal" por outro lado, é um jogo com produtos culturais, não envolve explicitamente a experiência primordial, não engaja o falante como pessoa no esforço de criação cultural. Por isso, ela mantém a instituição da fala, não cria (Amatuzzi, 1989).

Já a "fala original" ou "fala falante" é, essencialmente criativa. Um pensamento, antes nunca pensado, vai sendo formulado na medida em que as palavras vão sendo ditas no aqui e agora. Desse modo, através de uma "fala primeira", o novo sempre emerge, a pessoa sempre se cria e se transforma. Como descreve Merleau-Ponty (1996), na "fala original" existe uma identificação da fala com o pensamento e do pensamento com o sentimento, ambos vão se construindo e se manifestando, junto com o processo de significação total do sujeito, no momento presente, através das palavras.

Neste sentido, a pessoa enquanto sujeito dessa "fala primeira", torna-se sua própria fala, está plenamente identificada com ela, e na medida em que essa fala é sempre novidade, é, conseqüentemente, transformadora e criadora do próprio ser, ao mesmo tempo, que também é transformadora e criadora do mundo.

É o falar autêntico que cria o mundo segundo o homem e o homem para o mundo. (Amatuzzi 1989, p.29). 


\section{A criação do mundo e de si mesmo na "fala original" $e$ na obra de arte e a apreensão do sentido daquilo que é expres- so nessas manifestações.}

De acordo com Heidegger, homem e mundo não são realidades separadas; um não existe sem o outro; eles se constituem mutuamente na medida em que se relacionam. Dizer que o homem é um ser no mundo implica em afirmar esta indiscutível solidariedade. (Romero, 1997).

Monique Augras (1986) explica que a criação do mundo pelo homem se dá em duas dimensões: implícita e explicita. A primeira se refere à criação de um mundo particular, subjetivo, estruturado a partir da relação com o objeto e revelado através da palavra. Esse processo faz parte do cotidiano da vida humana. A dimensão explícita diz respeito à criação da obra de arte, que é a configuração objetiva, visível e externa desse mundo subjetivo, interno e invisível. Essas duas dimensões criativas, embora sendo estruturalmente diferentes, são formas de expressão e criação do ser no mundo. A obra deliberada ou explícita possui feições mais nítidas e conduz mensagens mais claras do que a obra implícita da vida; uma é esclarecedora da outra.

Merleau-Ponty (1996), sobre o tema da criação simultânea do homem e do mundo através da fala, explica que do mesmo modo que o mundo dos objetos passa a existir, a partir de sua denominação pelo sujeito, através da palavra, o mundo subjetivo de pensamentos e sentimentos se concretiza, na medida em que essas vivências são descritas e nomeadas verbalmente.

Neste sentido, podemos dizer que tanto o artista como o sujeito da "fala primeira", na medida em que se encontram inteiramente envolvidos e identificados com a expressão criativa de seu próprio ser, e uma vez que essa expressão gera sempre uma transformação e uma novidade, ambos estão criando o mundo e a si mesmos, enquanto se revelam de forma original através da fala ou da arte.

O mundo também é transformado a partir da expressão criativa de cada ser humano, porque todo ato criativo traz para fora algo novo e diferente, que inevitavelmente modificará o outro, desde que este seja capaz de apreender a novidade e o estranho contidos na mensagem proposta pelo artista ou pelo sujeito que professa uma "fala autêntica".

A respeito da questão da apreensão, por parte do espectador, do sentido da obra de arte, Augras (1986, p.91) comenta:

$O$ artista atua como criador do mundo. O pintor e o escultor transportam o espectador a uma nova dimensão da realidade. $O$ universo que propõe obedece às leis usuais da física, por apoiar-se em objeto concreto, mas ao 


\section{Carlene Tenório}

mesmo tempo sugere a inserção de outro sistema de relações, sutis, intemporais, cujo significado não pode ser apreendido de imediato, mas precisa ser desvendado pelo espectador

De fato, se a criação artística e a produção de uma "fala autêntica" é algo tão particular e essencial no sujeito, como é possível a compreensão, o esclarecimento desse enigma ou engajamento do outro nesse ato expressivo tão singular, íntimo e, por vezes, até surpreendente?

Amatuzzi (1989) explica que é preciso haver uma identificação por parte do espectador, ou seja, um introduzir-se no mundo daquele que se expressa criativamente, colocando-se no lugar dele, mergulhando na sua subjetividade, no sentido de vivenciar a sua experiência, mas sem nunca perder o contato com a própria experiência e subjetividade, sem nunca perder o caráter do "como se" fosse a outra pessoa. Em outras palavras, é preciso manter uma relação dialógica, uma relação EU - TU entre o espectador e a obra de arte, entre o ouvinte e a pessoa que fala, como descreve Buber (1979) em sua filosofia do diálogo. Segundo ele, a relação Eu-Tu constitui o único caminho possível para uma verdadeira apreensão da subjetividade do outro.

Merleau-Ponty (1996), abordando a questão da compreensão, por parte do leitor, daquilo que é expresso pelo escritor em sua filosofia, comenta que só é possível compreender uma filosofia introduzindo-se na maneira de existir desse pensamento, reproduzindo seu tom, o sotaque do filósofo. Ou seja, é preciso haver uma identificação vivencial entre leitor e escritor.

Com relação à obra de arte, sabemos que para que esta cumpra seu papel de transmitir uma mensagem nova, que é única e própria do artista, é preciso que aconteça uma certa identificação vivencial entre o espectador e o artista. A experiência vivida pelo artista, enquanto cria sua obra, é, de certo modo, também vivida pelo assistente. Este, ao apreciar uma obra de arte, se transporta para o mundo do artista, mas essa viagem só é possível na medida em que seu próprio mundo particular e sua subjetividade, de alguma forma, estiverem conectada com o mundo e com a subjetividade daquele que se expressa criativamente.

No entanto, nesse processo de apreensão da subjetividade do outro através do encontro, a própria subjetividade do interlocutor se transforma. Desse modo, o eu se cria na medida em que se relaciona com o tu. Enquanto o eu falante se cria em sua "fala original", o eu ouvinte também se constrói numa dimensão nova a partir dessa relação. Da mesma forma, podemos dizer que acontece essa transformação no artista que cria sua obra e na pessoa que contempla a arte.

Holanda (1998) explica que o Eu não se estabelece por si só, mas a partir da relação que cria e que o Eu-Tu é uma atitude de encontro entre dois seres sem 
limites interpostos, num face a face, onde os dois se confrontam e assim, Eu me descubro num $\mathrm{Tu}$, e este se descobre em mim, que passo a ser o seu Tu.

\section{O vazio primordial que antecede a obra de arte e a fala original; a morte e o renascimento no processo criativo}

De acordo com Merleau-Ponty (1996), a "fala primeira" é o pensamento em ato, não existe um pensamento precedente do qual ela seria a tradução, não existe uma idéia ou concepção à priori. O que existe antes dela não é o pensamento, mas sim a gestação de uma intenção significativa.

Este aspecto da "fala original" nos remete a um dos pressupostos básicos do existencialismo de Sartre (1970) no qual ele afirma que a "a existência precede a essência". Isto quer dizer que primeiro o homem existe e só a partir de sua existência, de suas escolhas e de sua práxis no mundo, é que sua essência se define e se revela.

Do mesmo modo que pensamentos e sentimentos são criados a partir de sua expressão na "fala primeira", a essência do ser humano também se cria a partir de sua atuação no mundo.

Merleau-Ponty, em “A Dúvida de Cézanne”, comenta:

"A arte é essencialmente criativa, ela traduz um pensamento ainda não pensado, não revelado ou esclarecido (...) a execução precede a concepção. Antes não existe nada, apenas uma febre vaga”. (1984, p.29).

Comparando a "fala primeira" com a produção artística, podemos dizer que a obra do artista também emerge do "nada", de um vazio ou de um silêncio primordial, onde o que existe é o caos, uma vibração, algo disforme e invisível que toma forma e torna-se visível, na medida em que a obra se concretiza.

Ainda sobre esse aspecto, Merleau-Ponty (1996) afirma que a palavra é um gesto lingüístico que rompeu o silêncio primordial, o qual precisa ser reencontrado, sob o ruído das falas, se quisermos compreender o gesto que expressa e dá sentido ao próprio existir do ser humano.

Este silêncio primordial, do qual emerge o gesto lingüístico, que estrutura a experiência e define a própria existência, nos faz lembrar das palavras de Augras (1986, p. 89), quando ela fala da criação do mundo:

"Antes da ação do demiurgo, existia apenas o caos. Até mesmo o Popol Vuh, o livro do Conselho dos Maias, ao afirmar que nada havia antes da criação, descreve: tudo estava invisível, tudo imóvel no céu. Não havia cons- 
trução, somente a água limitada, somente o mar calmo. Nada existia, somente a imobilidade, o silêncio nas trevas, na noite. Sós, os Construtores, os Formadores, os Dominadores, os Poderosos do Céu, os Parituros, os Genitores, estavam sobre a água, luz derramada”.

Observa-se que as características do caos são o silêncio e a imobilidade. A criação vai ser a palavra e o movimento, a significação e a mudança.

A “fala autêntica” ou "falante", explica Amatuzzi (1989), é a fala nova, na qual a intenção significativa se encontra em estado nascente. Podemos dizer, portanto, que a intenção significativa, que se encontra em estado gestacional, antes da "fala primeira", é uma experiência primordial. Essa experiência seria o constituinte dinâmico da significação do próprio sujeito e de seu mundo. Seria uma experiência pré-verbal que é descoberta pelo verbal.

A experiência primordial, na fenomenologia de Husserl se refere à vivência pré-reflexiva, na qual se dá a significação primeira do fenômeno ou do objeto percebido. Ela é anterior a qualquer reflexão ou elaboração cognitiva, na qual a experiência passa por uma tradução deformativa, segundo as circunstâncias e valores sócio-culturais, internalizados pelo sujeito. Desse modo, para que haja uma "fala original" ou uma produção artística, é preciso que o sujeito faça um retorno ao caos, ao silêncio primordial e entre em contato com a vivência préverbal ou pré-reflexiva, com a experiência originária da consciência, para que o novo possa surgir.

Mas esse retorno ao caos e esse contato com a experiência primordial, de onde emerge a criação, não é feito de modo tranqüilo ou isento de conflito e sofrimento. Todo ato criativo, segundo Jung, é precedido por uma vivência de luta, que é representado pelo retorno à prima matéria no processo alquímico.

Augras (1986, p.90) ao falar sobre o processo de criação do mundo diz:

"Muitos mitos contam a criação do mundo humano como um feito heróico, conquistado mediante guerras, até a organização do mundo é o resultado de uma retaliação. Depois de ter derrotado Tiamat e os seus exércitos, o herói babilônico Marduk corta o monstro em pedaços e a partir destes constrói o mundo. Em seguida cria o homem. Mas para animá-lo, é preciso o sangue de um deus. Um dos deuses vencidos no combate terá de ser sacrificado para dar vida a Lullû, o homem. A criação é um processo tão doloroso que até deuses devem ser imolados (...) toda criação requer uma destruição”.

A criação, portanto, implica em um processo de transformação, de destruição e reconstrução, através de lutas e conflitos, onde morrer naquilo que é velho e renascer naquilo que é novo, constitui o próprio movimento de renovação da 
vida, de criação da natureza. Desse modo, podemos afirmar que as pulsões de vida e de morte estão presentes no processo criativo.

A pulsão de morte se manifesta na tendência à repetição de um ciclo continuo, onde sempre se retorna às origens, ao nada, ao silêncio primordial, que embora esteja potencialmente cheio de vida, é vivenciado com dor e sofrimento, para só depois vir o renascimento, a renovação da vida. Esse processo cíclico de morte e de vida, que pertence à própria criação da natureza e que pertence também à criação da obra de arte, lembra a imagem descrita no mito de Prometeu, onde uma ave, repetidamente, devora seu fígado, enquanto este, repetidamente, se reconstitui e renasce, num ciclo contínuo de destruição e reconstrução, morte e vida.

\section{Referências}

AMATUZZI, M.M. (1989). O resgate da fala autêntica, Campinas, São Paulo: Papirus. AUGRAS, M. (1986). O ser da compreensão: Fenomenologia da Situação de Psicodiagnóstico, Petrópolis: Vozes.

BARBOSA, M.F. (1998). A noção de ser no mundo de Heideggere sua aplicação na Psicopatologia, Psicologia-Ciência e Profissão, Brasília: Conselho Federal e Regional de Psicologia, 18 (3): 2-13.

BUBER, M. (1982). Do Diálogo e do Dialógico, São Paulo: Perspectiva.

HOLANDA, A. F. (1998). Diálogo e psicoterapia: Correlação entre Carl Rogers e Martin Buber, São Paulo: Lemos Editorial.

MERLEAU-PONTY, M. (1984). A Dúvida de Cézanne, em Os Pensadores (p.23-126). São Paulo: Abril Cultural.

MERLEAU -PONTY, M. (1996). Fenomenologia da Percepção, São Paulo: MartinsFontes.

ROMERO, E. (1997). O Inquilino do Imaginário: Formas de Alienação e Psicopatologia, São Paulo: Lemos Editorial.

SARTRE, J. P. (1970). O Existencialismo é um Humanismo, Lisboa: Editorial Presença. 